\title{
MRI assessment of hepatocellular carcinoma after locoregional therapy
}

\author{
Rasha S. Hussein * (D), Wahid Tantawy and Yasser A. Abbas
}

\begin{abstract}
Liver cirrhosis and hepatocellular carcinoma (HCC) constitute one of the major causes of morbidity, mortality, and high health care costs worldwide. Multiple treatment options are available for HCC depending on the clinical status of the patient, size and location of the tumor, and available techniques and expertise. Locoregional treatment options are multiple. The most challenging part is how to assess the treatment response by different imaging modalities, but our scope will be assessing the response to locoregional therapy for HCC by MRI. This will be addressed by conventional MR methods using LI-RADS v2018 and by functional MR using diffusion-weighted imaging, perfusion, and highlighting the value of the novel intravoxel incoherent motion (IVIM).
\end{abstract}

Keywords: Hepatocellular carcinoma, Locoregional treatment, Magnetic resonance imaging, Treatment response of HCC, LI-RADS V2018

\section{Key points}

- To know the available locoregional therapies for HCC.

- To compare various criteria for Response Assessment in HCC.

- To highlight MRI criteria for LI-RADS v2018 in treatment response assessment for each locoregional therapy.

- To demonstrate some pitfalls in assessment after various available locoregional therapy and the available functional methods for treatment response assessment.

- To highlight the novel intravoxel incoherent motion (IVIM) which could be used as quantitative tool.

\section{Introduction}

Hepatocellular carcinoma (HCC) constitutes a major cause of morbidity, mortality, and high health care cost in Egypt. In the past decade, there is a rapid rise in prevalence of HCC among Egyptian patients with hepatitis $\mathrm{C}$ virus infection which is almost a twofold increase [1]. HCC is an aggressive tumor constituting the third leading cancer-related deaths worldwide [2]. Treatment options for HCC are variable depending on stage of HCC at the time of diagnosis. Curative treatments are surgical including resection or liver transplant. Other curative options could be via locoregional therapies, e.g., thermal ablation (radiofrequency ablation [RFA] and microwave ablation) or chemotherapy-based conventional transarterial chemoembolization (TACE) as a bridge for liver transplant. Palliative treatments are transcatheter therapies including TACE, drug-eluting bead TACE (DEB-TACE), bland transarterial embolization (TAE), transarterial radioembolization (TARE), or systemic therapy. Such locoregional therapies are more popular in Egypt due to the delayed diagnosis, excessive cost of surgical options, presence of portal hypertension, and the non-availability of matching donor [3]. Assessing treatment response is crucial in therapeutic planning to evaluate the

* Correspondence: rashasalah@med.asu.edu.eg

Radiology Department, Faculty of Medicine, Ain Shams University and MR

Unit of Misr Radiology Center, Cairo, Egypt 
early need of repeated treatment [4]. This assessment could be performed by CT or MRI with no definitive evidence of superiority of MRI over CT in treatment response assessment. The choice of imaging modality in treatment response is chosen according to availability, institutional preference, and expertise. CT is widely used and faster than MRI, yet some pitfalls occur especially after lipiodol-based TACE due to beaming artifact of lipiodol hindering the proper evaluation of residual viable tumor [5] (Fig. 1). Also, the obvious contrast resolution of MRI especially with subtracted images helps in discriminating post-therapy changes from residual or recurrent tumor as well as detecting newly developed lesions [6]. Moreover, MRI is superior to CT in the surveillance for patients after treatment to minimize radiation exposures and hazards of contrast agents especially if young-aged [5, 7-12].

\section{Main structure}

\section{Background of the available locoregional therapy}

The available locoregional therapies for HCC in Egypt are thermal ablation (RFA and microwave ablation), TACE, DEB-TACE, TAE, TARE, and percutaneous ethanol injection. Percutaneous ethanol injection is regressing due to the availability of RFA. According to the Barcelona Clinic Liver Cancer classification, tailored therapeutic options could be used according to every case scenario via a multidisciplinary team, e.g., performance status, Child-Pugh score, tumor size, location of
$\mathrm{HCC}$ and their number, presence of vascular invasion, portal hypertension, and extrahepatic spread [13].

In early-stage HCC, RFA is the best option with comparable results as surgical resection in terms of overall survival and disease-free survival [14]. In early-stage HCC, RFA shows complete response rates of $97 \%$ with 5-year survival rates of $68 \%$ [15]. RFA induces coagulative necrosis of the tumor by heat. However, the relation of vascular structures adjacent to tumor may induce heat-sink effect limiting the use of RFA due to the cooling effect by the adjacent vessel. Hence, the newer thermal ablative technique, microwave ablation, had emerged to overcome such problem. Moreover, it is more useful in larger tumors than RFA [16]. In intermediate-stage HCC, TACE is the best option either with conventional TACE or TACE with drug-eluting beads [17].

\section{MRI technique}

The MR study should be done on high-field MR machine, either a 1.5-T or 3.0-T unit. Torso-phased array coils and breath-hold technique should be advocated. Parallel imaging should be used to improve SNR by decreasing acquisition time. 3.0-T MRI offers higher SNR than $1.5 \mathrm{~T}$ but more vulnerable to susceptibility artifacts [18-20]. Conventional anatomical MR imaging should include axial FSE T2-weighted imaging (T2-WI) with and without fat saturation with controlled breathing, axial gradient-recalled echo (GRE) DIXON T1-weighted imaging (T1-WI). Multiplanar imaging is optional. Diffusion-weighted imaging (DWI) is obtained by a

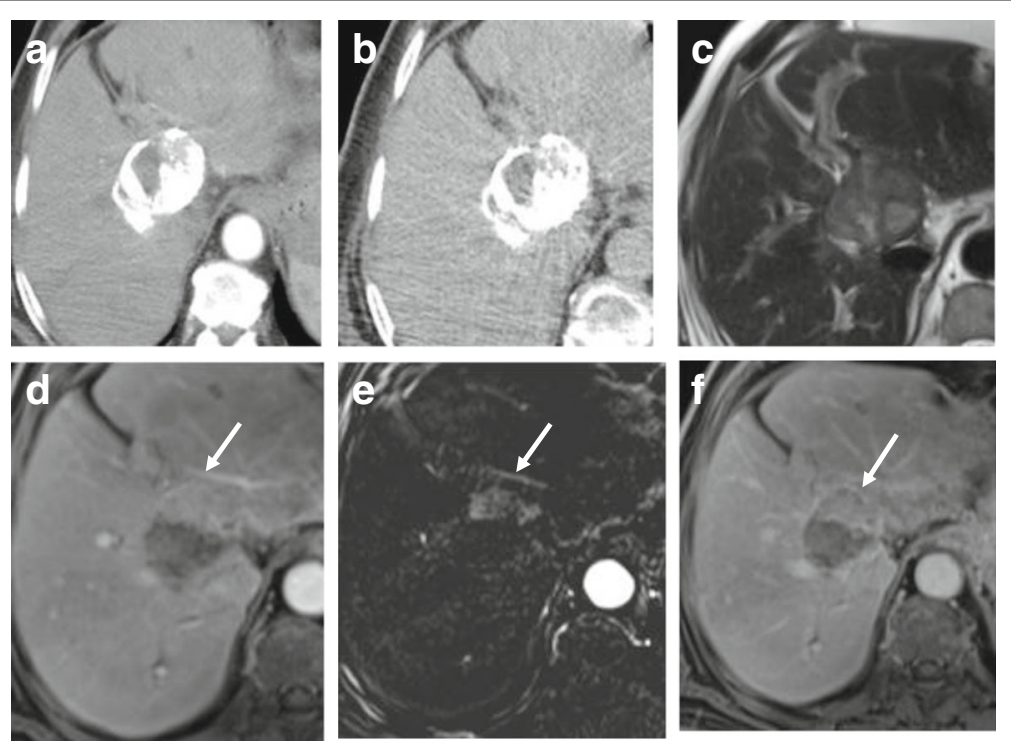

Fig. 1 CT versus MRI after TACE. a Arterial phase CT shows heterogenous lipiodol condensation without appreciable enhancement. b Delayed phase CT shows heterogenous lipiodol condensation without appreciable washout. c T2-WI shows a heterogenous signal. d Enhanced T1-WI in the arterial phase shows non-enhancement in most of the lesion with faintly enhancing peripheral nodule (arrow). e Subtracted image confirms non-enhancement in most of the lesion with a faintly enhancing peripheral nodule (arrow). $\mathbf{f}$ Enhanced T1-WI in the delayed phase shows washout of the faintly enhancing peripheral nodule (arrow). Final diagnosis is LR-TR viable which is highlighted by MRI, not by CT 
free-breathing monopolar-3D Diagonal planar echopulse sequence (EPI) using parallel imaging. Multiple $b$ values (at least two $b$ values: 0 and $800 \mathrm{~s} / \mathrm{mm}^{2}$ ) are used to generate ADC map and extract the ADC value. DWI has several limitations, e.g., poor SNR and susceptibility to several artifacts, including blurring, ghosting, and distortions especially for left lobe focal lesions. Also, the non-uniform fat suppression is one of the limitations of DWI on $3.0 \mathrm{~T}$. Multiple solutions were offered to overcome these limitations, e.g., multichannel coils, strong gradients, high magnetic fields, breath-hold and ECG-gated techniques (if feasible), and advanced software [20-23]. Axial 3D fat-suppressed GRE T1-weighted imaging before and after dynamic injection of extracellular gadoliniumbased contrast agents with an MR compatible pump injector was proposed. The dynamic study is performed with breath-hold in triphasic fashion: arterial phase (by bolus-tracking technique), portal venous phase (90 s), and delayed (equilibrium) at $3 \mathrm{~min}$. Subtracted images mainly from the arterial phase dynamic study could be extrapolated to highlight subtle enhancing parts and to get rid of the signal from any hemorrhagic or fatty elements. Dynamic contrast-enhanced MR (DCEMR) could be also performed.

\section{Treatment assessment criteria}

The Response Evaluation Criteria in Solid Tumors (RECIST), incorporating unidimensional measurements, was addressed to evaluate change in tumor size after systemic treatments regardless of changes in the vascularity or necrosis of the tumor [24, 25].

Effective locoregional therapy for HCC aims to induce tissue necrosis, which occurs even before size change occurs. Moreover, after locoregional therapy, the treated HCCs may show increased size due to edema, hemorrhage, and necrosis [26]. Due to these limitations of RECIST, new assessment criteria by the European Association for the Study of the Liver (EASL) were considered. It relies on assessing the enhancing component of the tumor, incorporating bidimensional measurements, i.e., modified WHO bidimensional measurements $[27,28]$. Then, modified RECIST (mRECIST) was introduced using the single largest diameter of the viable enhancing tumor during the arterial phase. Thereby, it is more practical for clinical use. According to EASL and the European Organisation for Research and Treatment of Cancer (EORTC), mRECIST criteria is the best used method after locoregional treatment for HCC on CT or MRI performed 1 month after therapy [29]. The mRECIST and EASL are good predictors of survival and for assessing anti-angiogenic effect of TACE [30-32] whereas there was no significant association between survival and RECIST 1.1 response [33].

Liver Imaging Reporting and Data Systems (LIRADS) v2018 is recently addressing treatment response criteria. It offers imaging criteria for viable and nonviable HCC and introduces additional terms of nonevaluable tumors as well as equivocal viability [34]. The mRECIST addresses patient-level assessments according to changes in the sum of diameters of target lesions. However, mRECIST does not address the variable imaging features following different locoregional therapies [33]. The new LI-RADS treatment response algorithm offers a comprehensive approach for lesion-by-lesion assessment, using either contrast-enhanced CT or MRI. The viable tumor measurements obtained from the LI-RADS algorithm could be used as a patient-level response assessment via mRECIST. The viability defined by LI-RADS treatment response algorithm, not only hyperenhancing portions, was developed to improve patient outcomes. Also, LI-RADS facilitate communication with the treating physician via a common language. The limitations of LI-RADS include no treatment-specific algorithm available and no ancillary features applied in treatment response assessment. Further research and user feedback are required to validate these data from the LI-RADS treatment response algorithm [35].

\section{LI-RADS treatment response algorithm LR-TR nonevaluable}

This is mentioned if there is image degradation or omission.

\section{LR-TR nonviable}

This is mentioned when there is no appreciable lesional enhancement or treatment-specific enhancement.

\section{LR-TR viable}

If there is nodular, mass-like, or thick irregular tissue enhancement in or along the treated lesion with any of the following: arterial phase hyperenhancement OR washout appearance OR enhancement similar to pretreatment, then it is considered a viable tumor.

\section{LR-TR equivocal}

It is assigned when there is uncertainty if the lesion is nonviable or viable with atypical enhancement.

So, to sum up, first, the LI-RADS treatment response algorithm is applied and then the viable enhancing component is measured at the longest dimension through the enhancing area of the treated lesion, not traversing the non-enhancing area. Lastly, if there is uncertainty 
between the two categories, the one reflecting lower certainty is chosen, i.e., LR-TR equivocal [34].

\section{MRI appearance after locoregional treatment Thermal ablation \\ Lesion assessment}

LR-TR nonevaluable Proper evaluation could not be done due to image degradation (Fig. 2).

LR-TR nonviable Thermal ablation induces coagulative necrosis. On T1-WI, this appears as a high signal or hyperintense peripheral rim while on T2-WI it appears as a low signal [36]. On the dynamic study, we prefer to use subtracted images to assess treatment response to nil any high signal within the lesions on the pre-contrast images facilitating discrimination between post-therapy changes and residual viable tumor [37]. On DWI, there is a hypointense central portion of the lesion while the periphery of the lesion shows hyperintensity with a lower ADC value than the surrounding hepatic parenchyma. This rim around the ablative zone is due to hyperemia and edema. The restricted diffusion of the edema occurs if it is a cytotoxic edema induced by the thermal stress. So, there is a challenge to discriminate post-treatment changes from residual tumors because both may cause restricted diffusion [38] (Figs. 3, 4, and 5).

\section{Perilesional hepatic parenchyma signal alterations and enhancements}

Sometimes, the adjacent hepatic parenchyma may show inflammatory changes. It shows a high signal on T2-WI with a low signal on an unenhanced T1-WI signal [39]. After contrast injection, this shows thin smooth rim enhancement [40]. This is known as transient hyperemia, and it is an expected finding in initial imaging after thermal ablation [41].
These immediate changes will disappear on subsequent imaging. This must be differentiated from a residual viable tumor which appears as nodular or thick peripheral enhancement [42-44] (Fig. 4).

LR-TR equivocal If there is a suspicious small zone of enhancement, then short-term follow-up after 3 months would be recommended [45].

LR-TR viable If there is early enhancement and delayed washout, this is considered as a residual viable tumor [44] (Fig. 6).

\section{Complications}

Complications of thermal ablation are minimal, and these include injury to blood vessels with formation of arteriovenous shunt. Subsequently, a wedge area of enhancement will be seen without washout. Other complications could be injury of bile ducts with biloma formation or injury to adjacent organs, e.g., the gall bladder, kidney, and bowel [46]. Infection and abscess formation is reported in the literature yet not common. Needle track seeding could also happen yet very rarely $[40,47]$.

\section{Transarterial chemoembolization Lesion assessment}

It is preferred to perform MR rather than $\mathrm{CT}$ in lipiodol-based embolization because the beaming artifact of lipiodol on CT hinders the proper assessment of a residual viable tumor [5], yet complete lipiodol uptake is strongly associated with a complete response at pathology and can be used as an additional criterion.

LR-TR nonviable A well-treated necrotic HCC shows variable signal intensity on unenhanced T1-WI and T2-WI due to liquefactive necrosis, hemorrhage, and
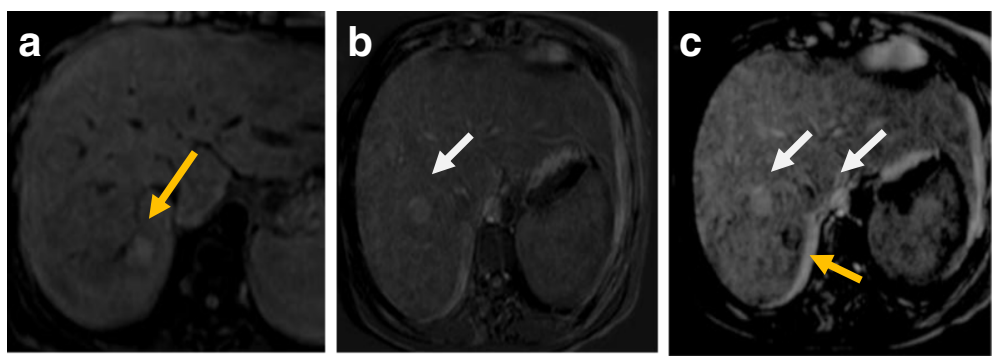

Fig. 2 MRI after RF. a Pre-contrast T1-WI fat-suppressed image shows the ablated HFL at subsegment VII (yellow arrow) with its bright signal due to coagulative necrosis. $\mathbf{b}$ Subtracted arterial phase at a higher level shows slice mis-registration between the pre-contrast and post-contrast image and mirror image of the aorta (white arrow). c Subtracted arterial phase at the HFL shows slice mis-registration between the pre-contrast and post-contrast image and mirror image of the aorta (white arrow) with eccentric faint enhancement at the lesion (not consistent with the residual viable tumor). Final diagnosis is LR-TR nonevaluable due to image degradation 

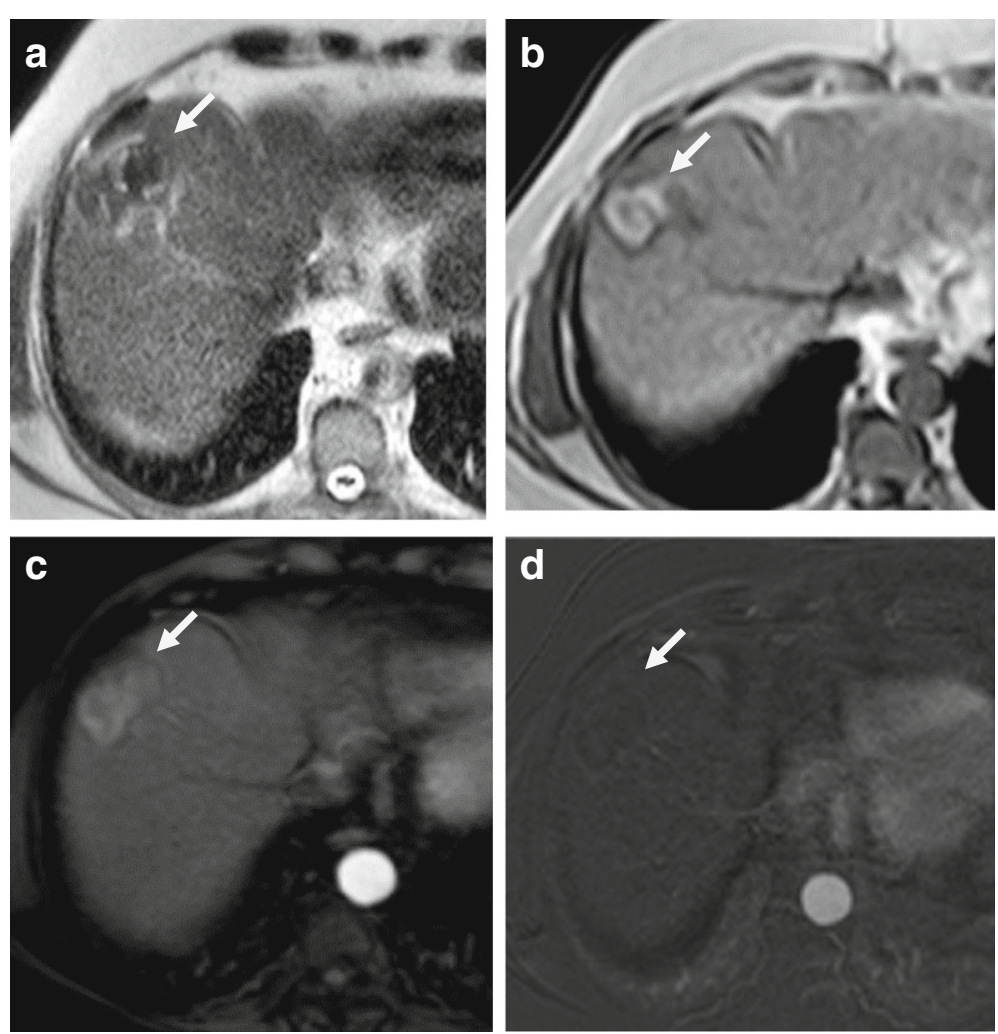

Fig. 3 LR-TR nonviable after RFA. a T2-WI shows that the treated lesion (arrow) has a low signal lesion (arrow). b T1-WI before contrast shows a high signal of the lesion. $\mathbf{c}$ Enhanced T1-WI in the arterial phase shows a high signal of the lesion that can be misinterpreted as an arterial hyperenhancing focal lesion. $\mathbf{d}$ Subtracted image of the enhanced T1-WI from the non-enhanced T1-WI shows no appreciable enhancement

inflammation [48]. A well-treated lesion shows no enhancement on dynamic study $[49,50]$.

\section{Perilesional hepatic parenchyma}

As in thermal ablation, transient hyperemia is seen at the periphery of the treated lesion.

LR-TR viable The presence of peripheral nodular enhancement with washout is an indication of the presence of a viable tumor either residual or re-growth [51] (Fig. 7).

\section{Complications}

Arterioportal shunts could occur after treatment due to injury of small hepatic arteries. Other complications include abscess formation or biloma [52]. Embolization of arteries other than the selected artery for the HCC can cause injury to the related organ and leak of the chemotherapy agent to the systemic circulation [53] (Figs. 8 and 9).

\section{Radioembolization}

It induces extensive inflammation of the hepatic parenchyma that can be misdiagnosed as a viable lesion $[54,55]$. The absence of contrast washout in delayed images and the gradual decreased enhancement as well as shrinkage of the lesion over time are a good sign for a well-treated focal lesion [56] (Figs. 10 and 11).

\section{Functional assessment}

Functional imaging is the use of advanced tools in assessing cellularity and vascularity of a hepatic focal lesion. They could give qualitative and quantitative data about tumor response even before morphological changes. These include diffusion and perfusion imaging [57].

\section{Diffusion-weighted imaging (DWI)}

DWI is a promising functional biomarker tool which assesses cellularity of the tissues depending on motion of water molecules at the extracellular/extravascular space. So, the highly cellular tissues show restricted motion of water molecules, yet the less cellular tissues allow free motion of water molecules [58, 59]. Using high $b$ values $\left(800-1000 \mathrm{~s} / \mathrm{mm}^{2}\right)$ allows suppression of background signals from the normal liver parenchyma and results in increased 

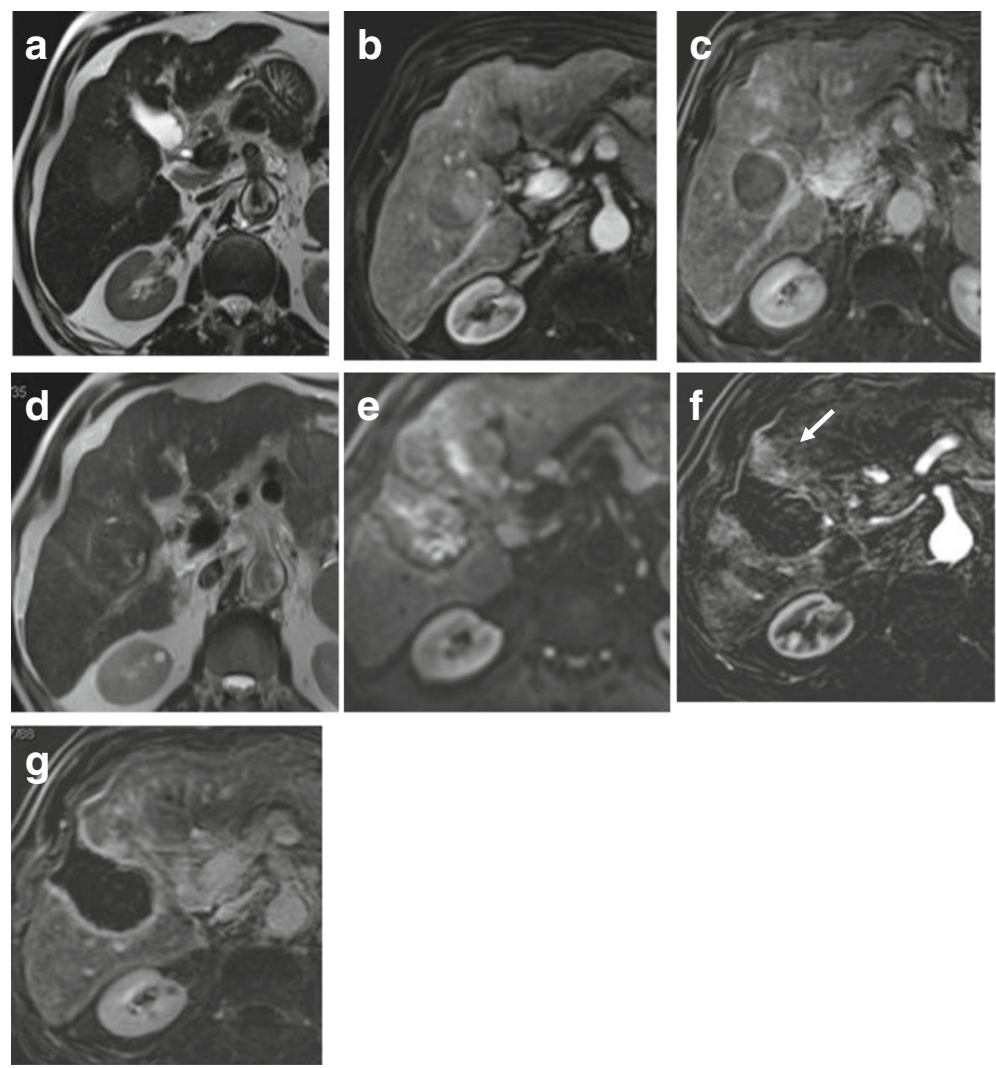

Fig. 4 Hepatic focal lesion before (a-c) and after RFA (d-g). a T2-WI shows a well-defined HFL of an intermediate signal. b Enhanced T1-WI in the arterial phase shows early arterial heterogeneous enhancement. $\mathbf{c}$ Enhanced T1-WI in the delayed phase shows washout with delayed capsule enhancement. $\mathbf{d}$ After treatment, T2-WI shows a low signal with peripheral hyperintensity. e DWI shows central areas of restriction. $\mathbf{f}$ Subtracted T1-WI arterial phase shows non-enhancement of the lesions with faint peripheral enhancement (arrow). g Delayed T1-WI shows persistent peripheral enhancement. Final diagnosis is LR-TR nonviable with post-therapy changes

contrast between the normal liver and lesions, facilitating the detection of hepatic focal lesions [60]. DWI enables the detection of small lesions around vessels and in the periphery of the liver which is sometimes challenging to be detected on T2-WI [61, 62]. DWI is also valuable especially when contrast media is contraindicated [63-65].

DWI is helpful in lesion characterization of a hepatic focal lesion (HFL) in a cirrhotic liver where a combination of restricted diffusion with arterial hyperenhancement is more likely to be HCC [66, 67]. Also, it is helpful in assessing tumoral versus bland thrombosis of the portal vein [68]. DWI and ADC show an additive value in detection of viable malignant hepatic focal lesions following locoregional therapy [58, 69, 70] (Fig. 12).

\section{Post-TACE assessment}

Kamel et al. [71] showed that there are different ADC values between necrotic portions compared to the viable tumors after TACE. They stated that the significant difference will be at 1-2 weeks after TACE and is correlated to enhancing components, which in turn also shows maximum difference from normal hepatic parenchyma after 1-2 weeks. Mannelli et al. [49] found that there was an insignificant difference between ADC values and subtracted images. The increase in the ADC value is an indication of good response to treatment reflecting less cellular packing [72]. This was also agreed with a study done by Chapiro et al. [73]. Bonekamp et al. [74] had investigated volumetric ADC changes after TACE at 1-month post-therapy and correlated with 6-month RECIST and mRECIST response. Volumetric ADC values are increased with objective response by mRECIST at 6 months with a sensitivity of $88.4 \%$ and specificity of $78.6 \%(p=0.001)$. Comparable results were obtained by using RECIST response criteria, yet with lower sensitivity and specificity. Sahin et al. [75] observed that an absolute increase in ADC values can differentiate viable/contrast-enhancing $\left(1.42 \pm 0.25 \times 10^{-3} \mathrm{~mm}^{2} / \mathrm{s}\right)$ and necrotic/non-enhancing $\left(2.22 \pm 0.31 \times 10^{-3} \mathrm{~mm}^{2} / \mathrm{s} ; p<0.001\right)$ tumor areas when compared to contrast enhancement patterns $6-8$ weeks after TACE. Yuan et al. [76] found ADC threshold of 

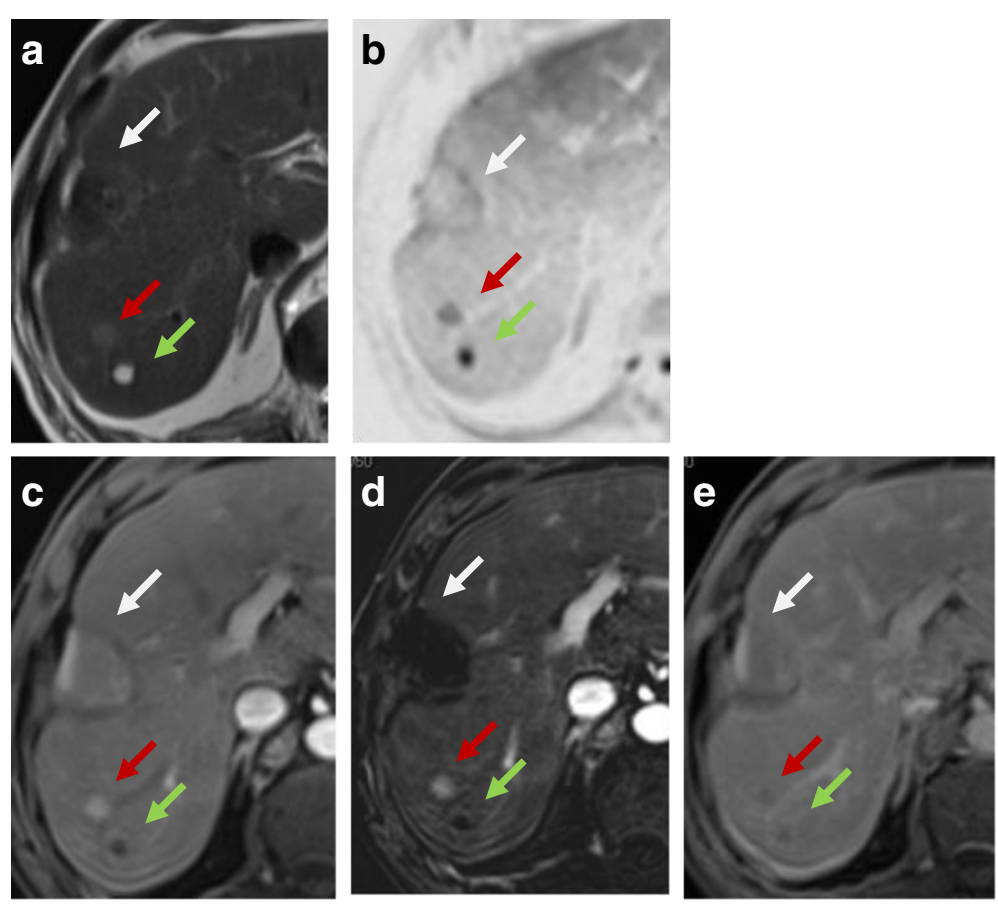

Fig. 5 Hepatic focal lesion after RFA. a T2-WI shows a well-defined treated subcapsular focal lesion (white arrow). Two other smaller lesions are seen posteriorly; one is of an intermediate signal (red arrow) and the other is of a high signal (green arrow). $\mathbf{b}$ Inverse of DWI shows no restriction of the treated lesion (white arrow), yet shows restriction of the other two lesions. ADC (not shown) shows T2 shine through of the posterior lesion (green arrow) with true restriction of the anterior lesion (red arrow). c Enhanced T1-WI in the arterial phase shows a high signal of the treated lesion that can be misinterpreted as an arterial hyperenhancing focal lesion. Note the enhancement of the anterior lesion and non-enhancement of the posterior small lesions. d Subtracted image shows no appreciable enhancement of the treated lesion and posterior lesion, yet shows definite enhancement of the redarrowed lesion. e Delayed T1-WI shows washout of the red-arrowed lesion. Final diagnosis is LR-TR nonviable, new small HCC, and small hepatic cyst

$1.84 \times 10^{-3} \mathrm{~mm}^{2} / \mathrm{s}$, which can differentiate necrotic from non-necrotic portions with $92.3 \%$ sensitivity and $100 \%$ specificity.

\section{Post-TARE and radiation therapy (RT)}

Kokabi et al. [77] demonstrated that absolute ADC value changes were an imaging biomarker for a
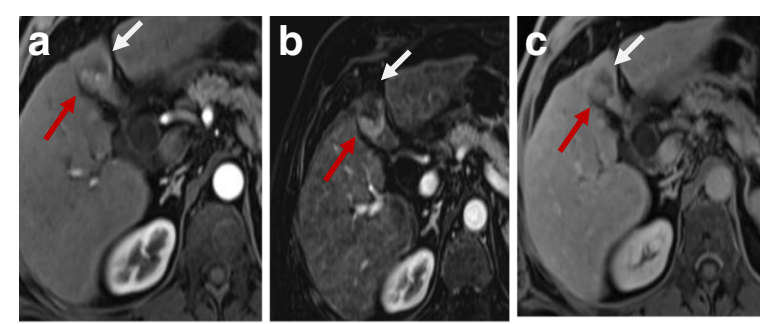

Fig. 6 Hepatic focal lesion after RFA. a Enhanced T1-WI in the arterial phase shows early arterial peripheral nodular enhancement (red arrow). b Subtracted T1-WI arterial phase shows true enhancement of the nodule (red arrow). c Enhanced T1-WI in the delayed phase shows washout with capsule enhancement (red arrow). Overall post-treatment assessment is LR-TR viable prompt response assessment in patients with HCC and portal vein thrombosis. Rhee et al. [78] showed that objective mRECIST responders after 3 months had a significantly greater mean ADC after 1 month than non-responders. Also, percent of ADC increase was also significantly higher in responders compared to non-responders at 3-month post-TARE. They found that an increase of $>30 \%$ in the ADC value after 3 months predicts treatment response with 90\% sensitivity and $100 \%$ specificity. Park et al. [79] found that DWI improves detection of a viable tumor after radiation therapy (RT) for HCC. Yu et al. [80] found that the local progression-free survival is related to the change in the ADC value before and after RT for HCC. Hence, if there is a contraindication for contrast agents, the ADC value and RECIST may substitute for mRECIST.

\section{Post-thermal ablation}

Post-thermal ablation induces hemorrhage which can mask the post-treatment expected ADC increase limiting the use of DWI in treatment response 

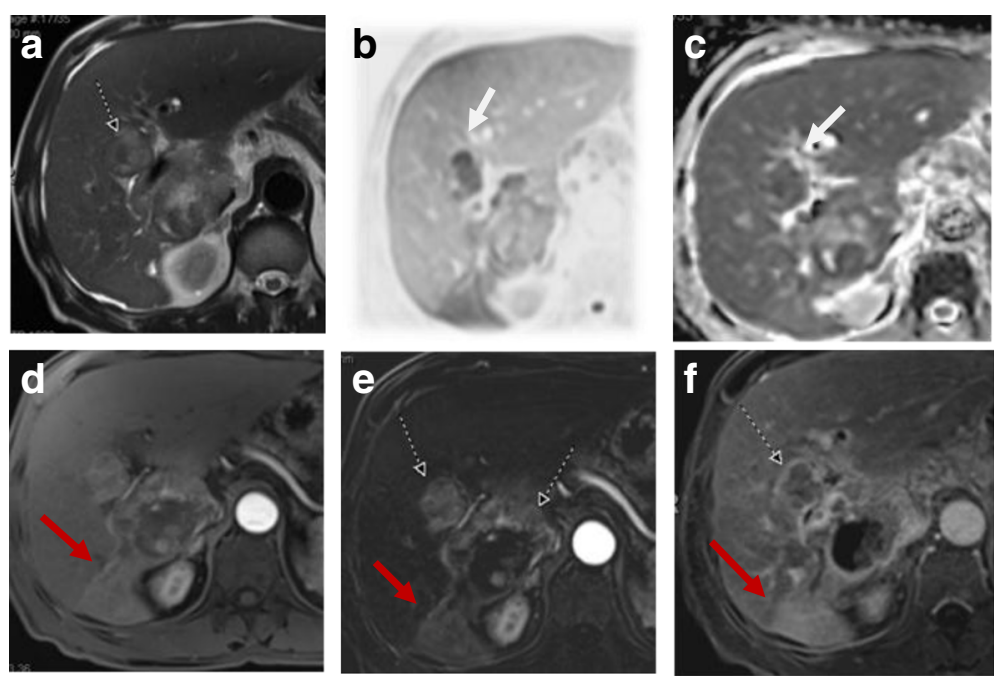

Fig. 7 Hepatic focal lesion after TACE. a T2-WI shows two well-defined HFLs of an intermediate to high signal. b, c DWI and ADC show central areas of true restriction for the smaller lesion (arrow) and heterogeneous restriction for the larger one. $\mathbf{d}$ Enhanced T1-WI in the arterial phase shows early arterial heterogeneous enhancement. e Subtracted T1-WI arterial phase shows true enhancement of the lesions (dashed arrows). There is a wedge area of enhancement as well (red arrow). f Enhanced T1-WI in the delayed phase shows washout with capsule enhancement (dashed arrow). The wedge enhancement shows delayed T1-WI persistent enhancement (red arrow). Overall post-treatment assessment is LR-TR viable with post-therapy changes

assessment [81, 82]. Schraml et al. [83] showed that the ADC value of signal alterations adjacent to the ablation zone may help in identification of local tumor progression and non-tumoral post-treatment changes.

\section{$A D C$ value assessment}

$\mathrm{ADC}$ is recently investigated as a pre-treatment biomarker to predict treatment response for TACE [49]. There is conflicting data in the literature about which tumors with high or low ADC values are good
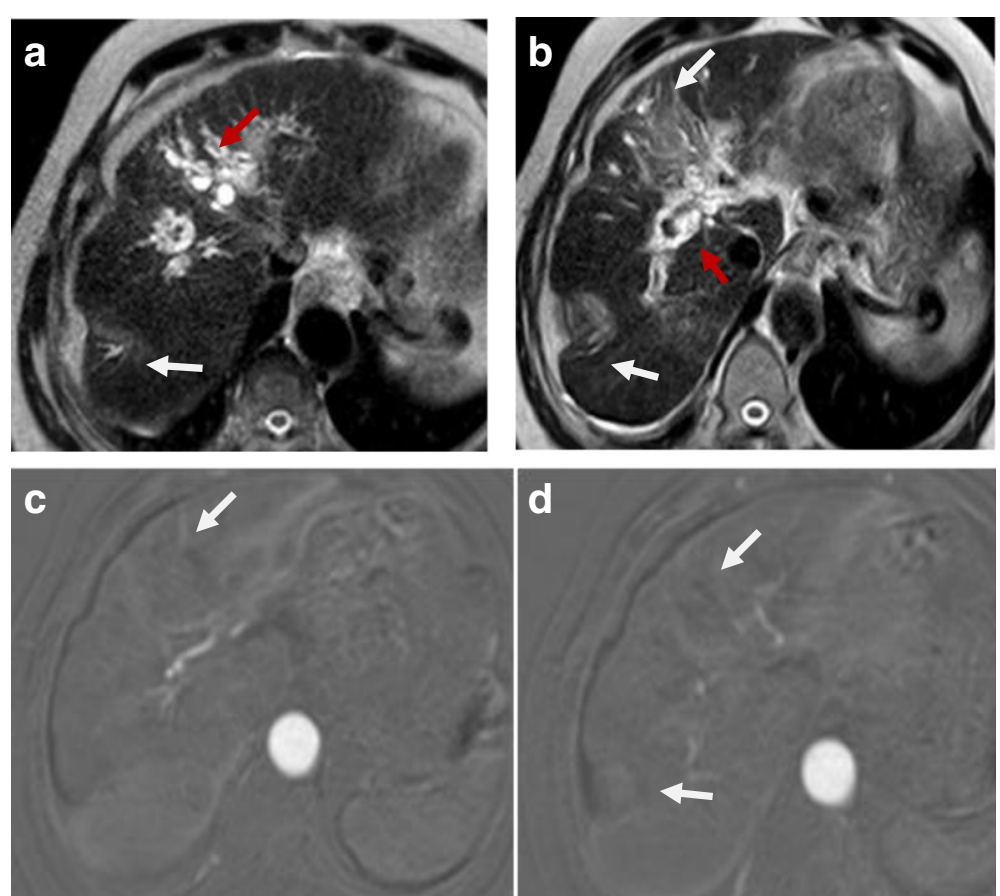

Fig. 8 Hepatic focal lesions after TACE. a, b T2-WI shows two well-defined HFLs of an intermediate to high signal (white arrows) with central biliary dilatation (red arrow). c, d Subtracted T1-WI arterial phase shows no enhancement of the lesions. Overall post-treatment assessment is LRTR nonviable with post-therapy biliary dilatation 

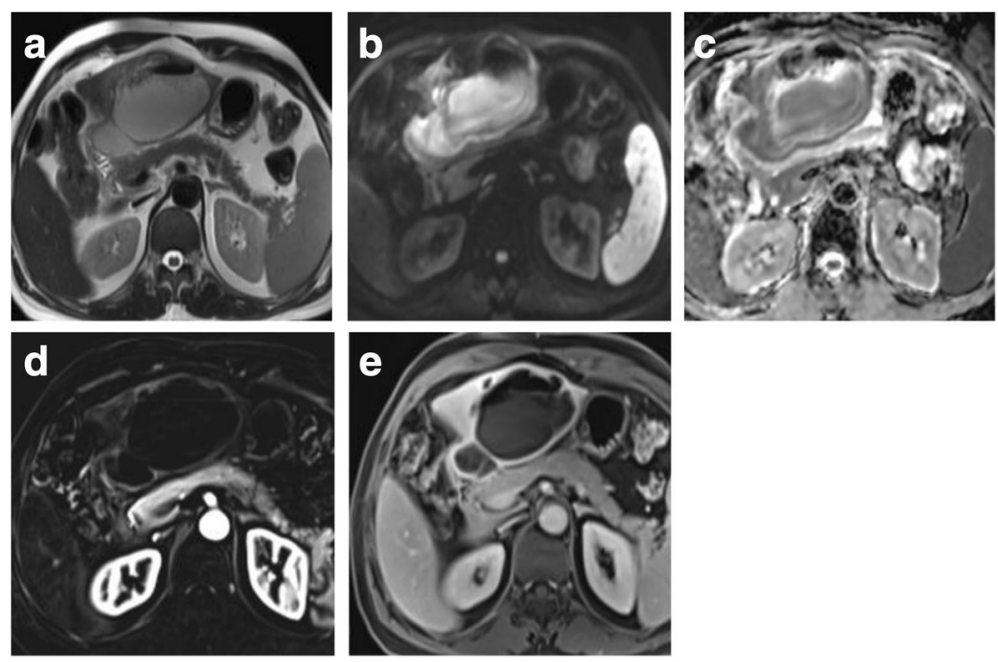

Fig. 9 Hepatic focal lesion after TACE. a T2-WI shows a well-defined cystic lesion at the treated focal lesion with air/fluid level. b, c DWI and ADC show central areas of true restriction. $\mathbf{d}$ Subtracted T1-WI arterial phase shows peripheral smooth wall enhancement of the lesion. e Post-contrast T1-WI delayed phase shows peripheral smooth wall enhancement of the lesion. Overall post-treatment assessment is LR-TR nonviable with posttherapy abscess formation

responders to TACE $[49,84,85]$. These conflicting data of DWI and ADC could be due to the use of different number of $b$ values in each study and complexity of lesion components of vascularity, hemorrhage, and necrosis [86, 87]. Padhani et al. [88] suggested that lesions with a higher vascularity exhibit a more restricted diffusion with lower ADC values. This could explain the better outcomes in lesions with lower pretreatment ADC values [84, 89-91]. Necrotic lesions show higher ADC values, and it is a sign of tumor aggressiveness. Necrotic lesions are poorly perfused and, therefore, could explain the poor outcomes in lesions with higher pretreatment ADC values [49, 84, 89, 91].

DWI has demonstrated a significant lower sensitivity and high specificity for tumor recurrence detection when compared to DCE-MRI. Therefore, DWI has no role in detection of recurrence [92].

\section{Perfusion}

Dynamic contrast-enhanced MRI (DCE-MRI) with IV contrast injection uses high-temporal images to assess changes in MR signal intensity (SI) over time. This has been used to detect liver fibrosis and cirrhosis and to assess tumor angiogenesis [93-95]. DCE-MRI can quantify vascularity of tumors and their response to angiogenic drugs especially for metastatic hepatic focal lesions and to sorafenib treatment. The obtained values via tracer kinetic modeling could be used in future therapeutic monitoring [96-102]. There are few prior studies for
DCE-MRI assessing HCC lesions especially after locoregional therapy [98, 103, 104]. Taouli et al. [99] have found differences in perfusion parameters between untreated HCCs and the background liver with higher arterial hepatic blood flow and arterial fraction, lower portal venous hepatic blood flow for HCCs, and no difference in distribution volume and mean transient time (MTT) (Fig. 13). Moreover, they found a decrease in arterial fraction, arterial hepatic blood flow, and distribution volume and an increase in portal venous hepatic blood flow after TACE. Sahani et al. [105] quantified perfusion on dynamic CT in patients $(n=30)$ with untreated HCC. They found that HCCs had higher blood flow, blood volume, and permeability-surface area product compared with the liver parenchyma, but MTT was lower in tumors. Abdullah et al. [94] assessed perfusion parameters in HCCs $(n=26)$ and colorectal metastases $(n=24)$. They found significantly higher arterial hepatic blood flow, portal venous hepatic blood flow, total hepatic blood flow, and distribution volume in HCCs compared with metastases. Also, they found significantly lower MTT in HCCs in comparison to metastases. They also found that HCCs showed higher portal venous hepatic blood flow than arterial hepatic blood flow. Dynamic CT has a direct linear relation between signal enhancement and iodine concentration making it superior to DCE-MRI. Yet, perfusion CT has a disadvantage of radiation exposure, especially for follow-up studies. Also, multiparametric tools of MRI with DCE-MRI 

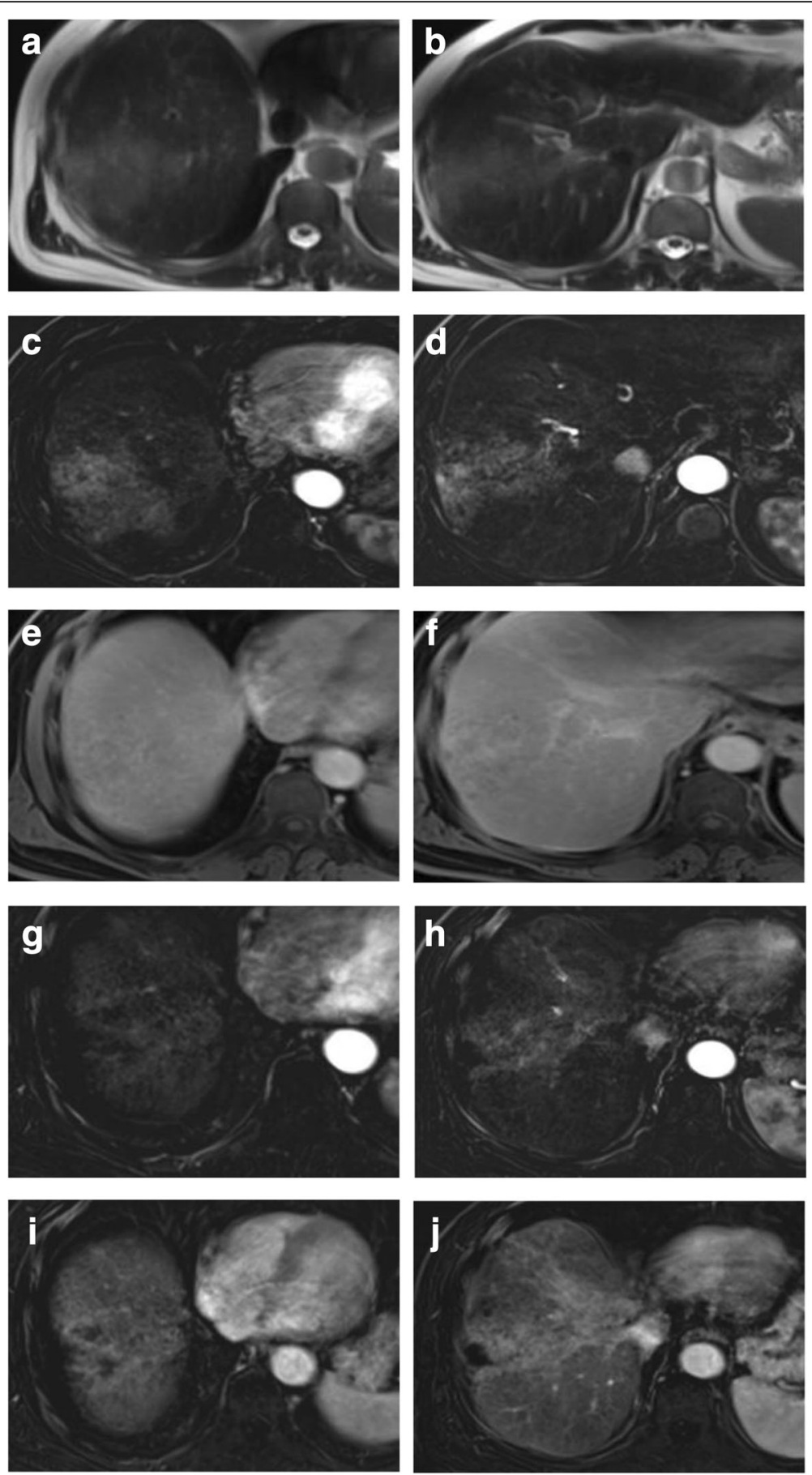

Fig. 10 Hepatic focal lesion before and after TARE. a, b T2-WI shows an ill-defined HFL of an intermediate signal. c, d Subtracted enhanced T1-WI in the arterial phase shows early arterial heterogeneous enhancement. e, f Enhanced T1-WI in the delayed phase shows heterogenous washout. $\mathbf{g}$, $\mathbf{h}$ After treatment, subtracted T1-WI arterial phase shows non-enhancement of the upper portion of the lesion with faint enhancement lower portion. $\mathbf{i}$, j Delayed T1-WI shows delayed and persistent enhancement of the lesion due to massive fibrosis. Final diagnosis is LR-TR nonviable with post-therapy changes

and diffusion-weighted MRI have the advantage over dynamic $\mathrm{CT}$ in better characterization of angiogenic activity and treatment response of HCC to TACE [99].

\section{Recent advances in MRI}

Intravoxel incoherent motion (IVIM)

IVIM is a novel MR technique which has been introduced to study both diffusion and perfusion effects on masses 

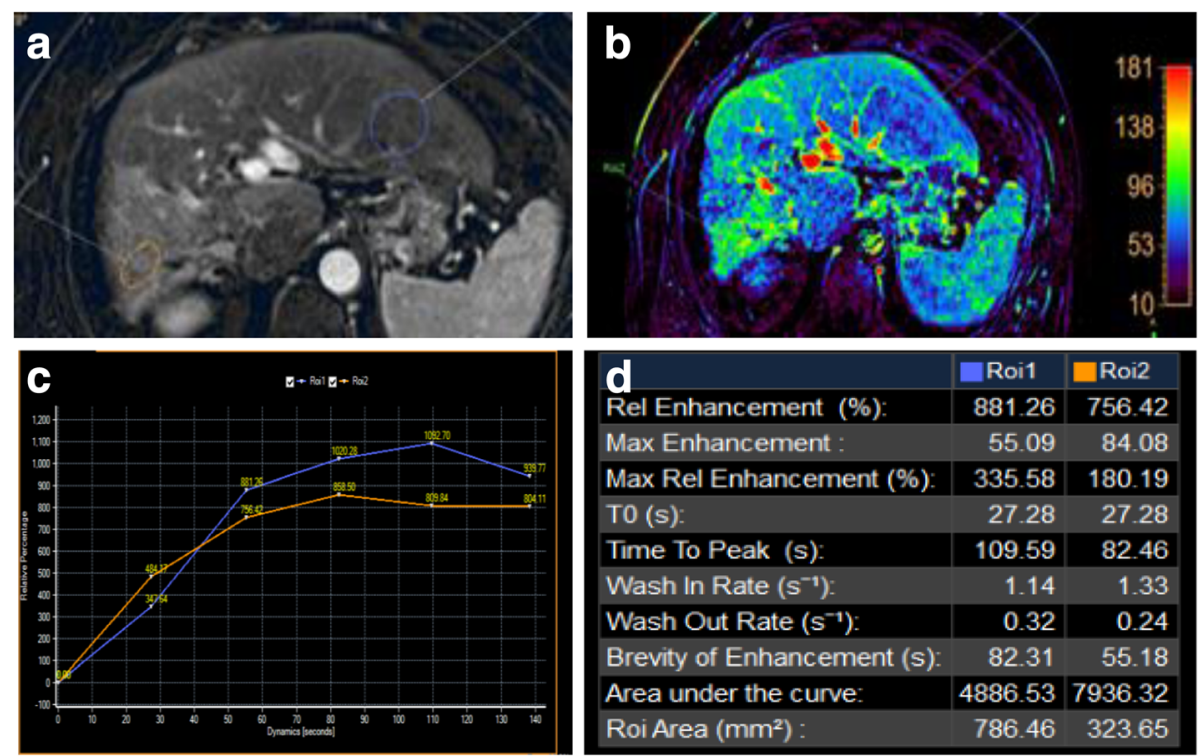

Fig. 11 Hepatic focal lesion after TARE. a Subtracted enhanced T1-WI in the arterial phase shows faint enhancement of the treated right lobe (ROI 2 "orange") compared to untreated hepatic parenchyma (ROI 1 "blue"). b T1 perfusion map (max. relative enhancement) shows mild increased blood flow to the treated right lobe. c Time-intensity curves on the treated right lobe (orange) and untreated left lobe (blue) show an uprising slope and followed by a plateau for the lesion due to fibrosis. $\mathbf{d}$ Semi-quantitative data for both ROls show decreased max. relative enhancement, time to peak, wash in rate, and wash out rate of the treated hepatic parenchyma compared to the rest of the hepatic parenchyma. Final diagnosis is LR-TR nonviable with post-therapy changes

without the need of intravenous contrast injections and is specifically helpful for patients with renal impairment, with contrast allergy, or with fear of long-term effects of gadolinium deposition. This technique can separate pure diffusion characteristics (D) from pseudo-diffusion caused by microscopic circulation in tissues, with also calculation of perfusion characteristics (pseudo-diffusion coefficient $\left.D^{*}\right)$ and its proportion (perfusion fraction fp) [106].

Woo et al. [107] and Mürtz et al. [108] found a significant correlation between IVIM-derived parameter
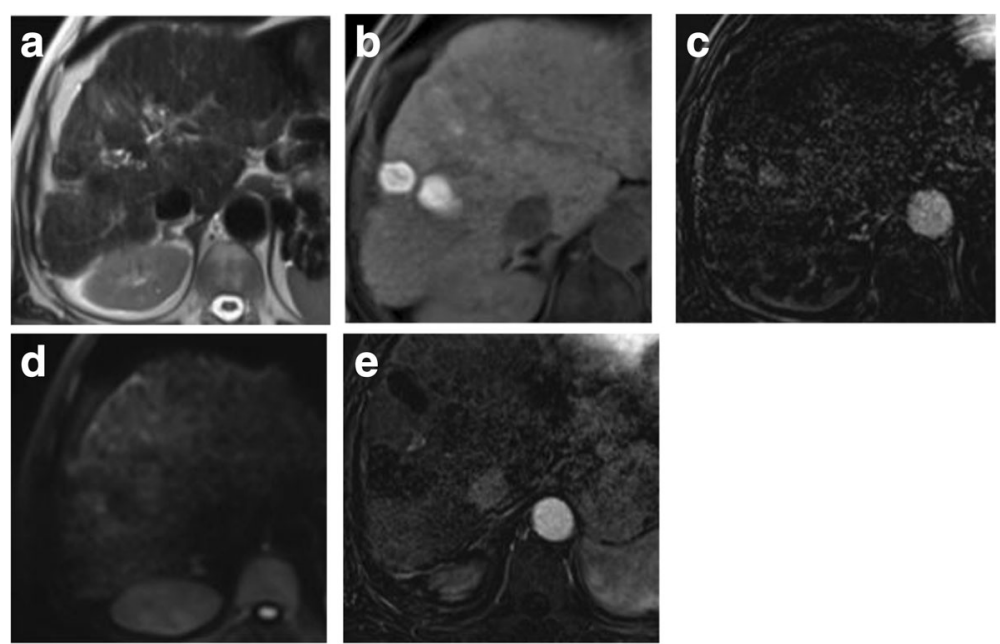

Fig. 12 Two hepatic focal lesions after old RFA. a T2-WI shows a hypointense signal of the treated focal lesions. b Pre-contrast T1 fat-suppressed image shows the ablated HFLs with their bright signal due to coagulative necrosis. c Subtracted T1-WI arterial phase shows newly developed faint enhancement of the lesions. $\mathbf{d}$ DWI shows no true restriction corresponding to the enhancement. e Subtracted T1-WI arterial phase after a 3-month interval shows no enhancement of the lesions. Initial post-treatment assessment by LI-RADS V2018 is LR-TR equivocal that proved to be nonviable after a short-interval follow-up. DWI was consistent with LR-TR nonviable from the start with no restriction initially and on the followup (not shown) 

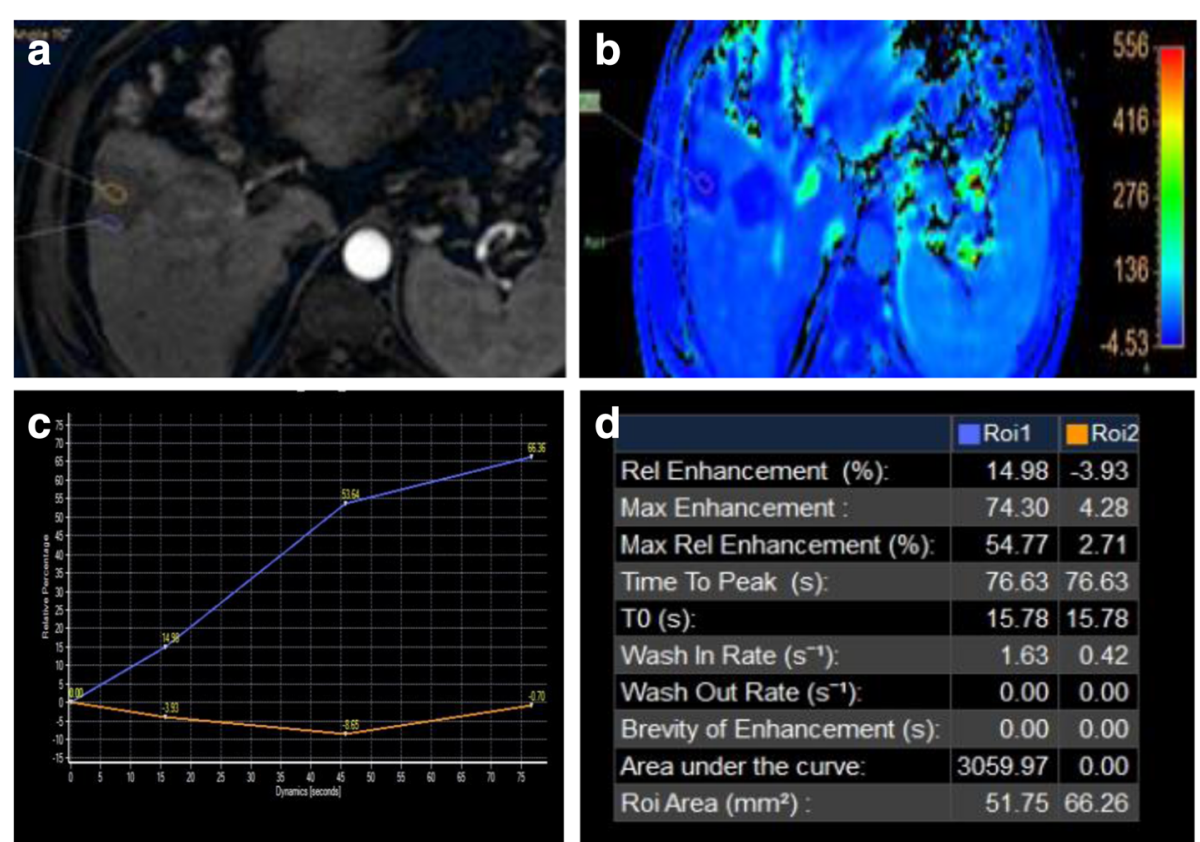

d
\begin{tabular}{|l|r|r|}
\hline Rel Enhancement (\%): & Roi1 & Roi2 \\
\hline Max Enhancement : & 14.98 & -3.93 \\
\hline Max Rel Enhancement (\%): & 74.30 & 4.28 \\
\hline Time To Peak (s): & 76.77 & 2.71 \\
\hline T0 (s): & 15.78 & 76.63 \\
\hline Wash In Rate $\left(\mathrm{s}^{-1}\right):$ & 15.78 \\
\hline Wash Out Rate $\left(\mathrm{s}^{-1}\right)$ : & 0.00 & 0.42 \\
\hline Brevity of Enhancement (s): & 0.00 & 0.00 \\
\hline Area under the curve: & 3059.97 & 0.00 \\
\hline Roi Area (mm $\left.{ }^{2}\right):$ & 51.75 & 66.26 \\
\hline
\end{tabular}

Fig. 13 Two hepatic focal lesions after RFA. a Subtracted enhanced T1-WI in the arterial phase shows faint enhancement of the periphery of the treated HFLs (ROI 1 "blue") compared to the center of HFLs (ROI 2 "orange"). b T1 perfusion map (max. relative enhancement) shows mild increased blood flow peripherally. c Time-intensity curves on the periphery of the treated HFLs (blue) and their center (orange) show an uprising slope due to inflammation. $\mathbf{d}$ Semi-quantitative data for both ROls show significant decreased max. relative enhancement of the center of treated HFLs compared to the periphery. Final diagnosis is LR-TR nonviable with post-therapy changes
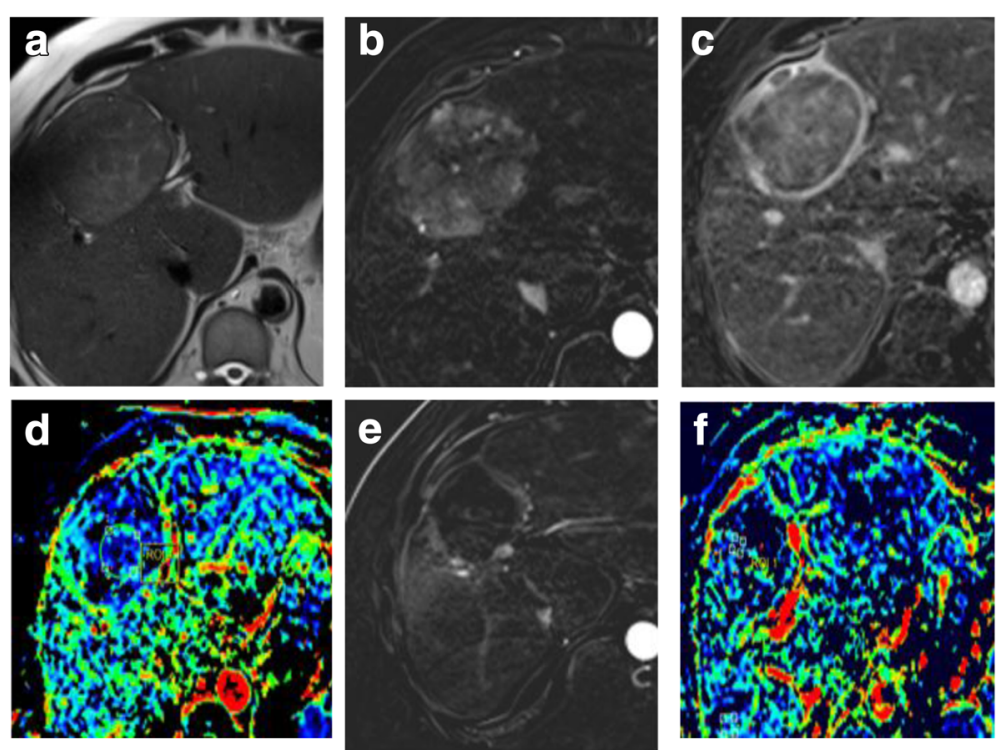

Fig. 14 Hepatic focal lesion before and after TACE with IVIM assessment. a T2-WI shows a well-defined HFL of an intermediate signal. b Subtracted enhanced T1-WI in the arterial phase shows early arterial heterogeneous enhancement. c Enhanced T1-WI in the delayed phase shows washout with delayed capsule enhancement. $\mathbf{d} F$ map of IVIM shows a high $F$ value due to increased microcirculation. e Post-treatment subtracted T1-WI arterial phase shows non-enhancement of the lesion. f Post-treatment F map of IVIM shows a reduced $F$ value due to tumor necrosis. Final diagnosis is LR-TR nonviable 
(fp) and percent of arterial enhancement whether in the initial diagnosis of $\mathrm{HCC}$ or after the locoregional therapy. Hence, it could be used after locoregional therapy to distinguish responders from non-responders especially if there is contraindication for contrast administration (Fig. 14).

Regarding D and ADC data, D-derived IVIM parameter was better than the ADC value to assess tumor necrosis after locoregional therapy for HCC. This higher accuracy of D-derived IVIM parameter can be explained by the fact that ADC is a nonspecific value that contains combined information on tissue cellularity (D) and perfusion (microcirculation), causing opposite effects on the measurement of ADC, resulting in decreased sensitivity and specificity. However, D-derived IVIM parameter eliminates this perfusion (microcirculation) contaminated ADC values, allowing pure measurements of tissue cellularity [108, 109]. So IVIM is a promising tool for hepatic focal lesion assessments before and after locoregional therapy especially without the need for contrast injection.

\section{Summary}

The LI-RADS v2018 is now the cornerstone in daily practice for evaluating treatment response of HCC after RFA and TACE, based on enhancement criteria of the treated focal lesion which is better correlated with subtracted images to omit post-treatment changes of coagulative necrosis and hemorrhage, because it is an easy and accurate method. However, it is more challenging to rely on this criterion alone especially after TARE due to complexity of post-treatment changes. Yet, the DWI/ADC value can help in the fine tuning of decision making in challenging equivocal cases especially if there is mismatch between diffusion restriction and enhancement to avoid unnecessary repeated treatment. Conventional MRI could not predict tumor grade, aggressiveness, angiogenesis, and hypoxia. Here comes the role of non-invasive MRI functional imaging including DWI, perfusion-weighted imaging, and the novel IVIM to be used as biomarkers to assess early treatment response of HCC to locoregional therapy especially after TACE and TARE. These functional data are better combined with morphological data to improve the diagnostic and prognostic criteria for postlocoregional treatment assessment of HCC. Ultimately, many studies are needed to validate a non-invasive algorithm based on multiparametric MRI to predict response of $\mathrm{HCC}$ and minimize the variability of the quantitative MRI metrics.

\section{Abbreviations}

D*: Pseudo-diffusion coefficient; fp: Perfusion fraction; D: Pure diffusion characteristics; DEB-TACE: Drug-eluting bead TACE; EASL: European Association for the Study of the Liver; EORTC: European Organisation for Research and Treatment of Cancer; HCC: Hepatocellular carcinoma;
HFL: Hepatic focal lesion; IVIM: Intravoxel incoherent motion; LI-RADS: Liver Imaging Reporting and Data System; mRECIST: Modified RECIST;

RECIST: Response Evaluation Criteria in Solid Tumors; RFA: Radiofrequency ablation; SNR: Signal-to-noise ratio; TACE: Chemotherapy-based conventional transarterial chemoembolization; TAE: Bland transarterial embolization;

TARE: Transarterial radioembolization

Acknowledgements

The cases from this study were performed at Misr Radiology Center. IVIM WIP used was provided by Siemens Healthcare.

Funding

The authors declare that this study did not received any funding.

Availability of data and materials

Data generated or analysed during this study are included in this published article.

Authors' contributions

All authors read and approved the final manuscript.

Ethics approval and consent to participate

The study was approved by our Institutional Review Board at Misr Radiology Center and informed consent was waived.

Consent for publication

Not applicable.

\section{Competing interests}

The authors declare that they have no competing interests.

\section{Publisher's Note}

Springer Nature remains neutral with regard to jurisdictional claims in published maps and institutional affiliations.

Received: 3 April 2018 Accepted: 3 January 2019

Published online: 29 January 2019

References

1. Shaker MK (2016) Epidemiology of HCC in Egypt. Gastroenterol Hepatol 4(3): 00097

2. Arif-Tiwari H, Kalb B, Chundru S et al (2014) MRI of hepatocellular carcinoma: an update of current practices. Diagn Interv Radiol 20:209-221

3. Lin S, Hoffmann K, Schemmer P (2012) Treatment of hepatocellular carcinoma: a systematic review. Liver Cancer 1:144-158

4. Chung JC, Naik NK, Lewandowski RJ et al (2010) Diffusion-weighted magnetic resonance imaging to predict response of hepatocellular carcinoma to chemoembolization. World J Gastroenterol 16(25):3161-3167

5. Kloeckner R, Otto G, Biesterfeld S, Oberholzer K, Dueber C, Pitton MB (2010) $M D C T$ versus MRI assessment of tumor response after transarterial chemoembolization for the treatment of hepatocellular carcinoma. Cardiovasc Intervent Radiol 33:532-540

6. Yaghmai V, Besa C, Kim E, Gatlin JL, Siddiqui NA, Taouli B (2013) Imaging assessment of hepatocellular carcinoma response to locoregional and systemic therapy. AJR Am J Roentgenol 201:80-96

7. Choi JY, Lee JM, Sirlin CB (2014) CT and MR imaging diagnosis and staging of hepatocellular carcinoma: part I. Development, growth and spread: key pathologic and imaging aspects. Radiology 272:635-654

8. Yu NC, Chaudhari V, Raman SS et al (2011) CT and MRI improve detection of hepatocellular carcinoma, compared with ultrasound alone, in patients with cirrhosis. Clin Gastroenterol Hepatol 9:161-167

9. Qian MY, Yuwei J R, Angus P, Schelleman T, Johnson L, Gow P (2010) Efficacy and cost of a hepatocellular carcinoma screening program at an Australian teaching hospital. J Gastroenterol Hepatol 25:951-956

10. Singal A, Volk ML, Waljee A et al (2009) Meta-analysis: surveillance with ultrasound for early-stage hepatocellular carcinoma in patients with cirrhosis. Aliment Pharmacol Ther 30:37-47

11. Santi V, Trevisani F, Gramenzi A et al (2010) Semiannual surveillance is superior to annual surveillance for the detection of early hepatocellular carcinoma and patient survival. J Hepatol 53:291-297 
12. Bruix J, Sherman M (2005) Management of hepatocellular carcinoma. Hepatology 42:1208-1236

13. Forner A, Llovet JM, Bruix J (2012) Hepatocellular carcinoma. Lancet 379: $1245-1255$

14. Chen MS, Li JQ, Zheng $Y$ et al (2006) A prospective randomized trial comparing percutaneous local ablative therapy and partial hepatectomy for small hepatocellular carcinoma. Ann Surg 243:321-328

15. Livraghi T, Meloni F, Di Stasi M et al (2008) Sustained complete response and complications rates after radiofrequency ablation of very early hepatocellular carcinoma in cirrhosis: is resection still the treatment of choice? Hepatology 47:82-89

16. Chinnaratha MA, Chuang MY, Fraser RJ, Woodman RJ, Wigg AJ (2016) Percutaneous thermal ablation for primary hepatocellular carcinoma: a systematic review and meta-analysis. J Gastroenterol Hepatol 31 (2):294-301

17. Lammer J, Malagari K, Vogl T et al (2010) Precision V investigators. Prospective randomized study of doxorubicin-eluting-bead embolization in the treatment of hepatocellular carcinoma: results of the PRECISION V study. Cardiovasc Intervent Radiol 33:41-52

18. Bammer R, Keeling SL, Augustin M et al (2001) Improved diffusion-weighted single-shot echo-planar imaging (EPI) in stroke using sensitivity encoding (SENSE). Magn Reson Med 46:548-554

19. Taouli B, Martin AJ, Qayyum A et al (2004) Parallel imaging and diffusion tensor imaging for diffusion-weighted MRI of the liver: preliminary experience in healthy volunteers. AJR Am J Roentgenol 183: 677-680

20. Rosenkrantz AB, Oei M, Babb JS, Niver BE, Taouli B (2011) Diffusionweighted imaging of the abdomen at 3.0 Tesla: image quality and apparen diffusion coefficient reproducibility compared with 1.5 Tesla. J Magn Reson Imaging 33:128-135

21. Koh DM, Collins DJ (2007) Diffusion-weighted MRI in the body: applications and challenges in oncology. AJR Am J Roentgenol 188:1622-1635

22. Baliyan V, Das CJ, Sharma S, Gupta AK (2014) Diffusion-weighted imaging in urinary tract lesions. Clin Radiol 69:773-782

23. Chandarana H, Taouli B (2010) Diffusion and perfusion imaging of the liver. Eur J Radiol 76:348-358

24. Therasse P, Arbuck SG, Eisenhauer EA et al (2000) New guidelines to evaluate the response to treatment in solid tumors: European Organization for Research and Treatment of Cancer, National Cance Institute of the United States, National Cancer Institute of Canada. J Natl Cancer Inst 92:205-216

25. Eisenhauer EA, Therasse P, Bogaerts J et al (2009) New response evaluation criteria in solid tumours: revised RECIST guideline (version 1.1). Eur J Cancer 45:228-247

26. Suzuki C, Jacobsson H, Hatschek T et al (2008) Radiologic measurements of tumor response to treatment: practical approaches and limitations. Radiographics 28:329-344

27. Llovet JM, Di Bisceglie AM, Bruix J et al (2008) Design and endpoints of clinical trials in hepatocellular carcinoma. J Natl Cancer Inst 100: 698-711

28. Bruix J, Sherman M, Llovet JM et al (2001) Clinical management of hepatocellular carcinoma: conclusions of the Barcelona-2000 EASL conference-European Association for the Study of the Liver. J Hepatol 35:421-430

29. European Association for the Study of the Liver, European Organisation for Research and Treatment of Cancer (2012) EASL-EORTC clinical practice guidelines: management of hepatocellular carcinoma. J Hepatol 56:908-943

30. Shim JH, Lee HC, Kim SO et al (2012) Which response criteria best help predict survival of patients with hepatocellular carcinoma following chemoembolization? A validation study of old and new models. Radiology 262:708-718

31. Kim BK, Kim KA, Park JY et al (2013) Prospective comparison of prognostic values of modified response evaluation criteria in solid tumours with European Association for the Study of the Liver criteria in hepatocellular carcinoma following chemoembolisation. Eur J Cancer 49:826-834

32. Gillmore R, Stuart S, Kirkwood A et al (2011) EASL and mRECIST responses are independent prognostic factors for survival in hepatocellular cancer patients treated with transarterial embolization. J Hepatol 55:1309-1316

33. Lencioni R, Llovet JM (2010) Modified RECIST(mRECIST) assessment for hepatocellular carcinoma. Semin Liver Dis 30:52-60
34. American College of Radiology. CT/MRI LI-RADS v2017 core. https://www. acr.org/Clinical-Resources/Reporting-and-Data-Systems/LI-RADS/CTMRI-LI-RADS-v2018-Core.pdf?la=en. Accessed 24 Sept 2018

35. Kielar A, Fowler KJ, Lewis S et al (2018) Locoregional therapies for hepatocellular carcinoma and the new LI-RADS treatment response algorithm. Abdom Radiol (NY) 43:218-230

36. Dromain C, de Baere T, Elias D et al (2002) Hepatic tumors treated with percutaneous radio-frequency ablation: CT and MR imaging follow-up. Radiology 223:255-262

37. Winters SD, Jackson S, Armstrong GA, Birchall IW, Lee KH, Low G (2012) Value of subtraction MRI in assessing treatment response following imageguided loco-regional therapies for hepatocellular carcinoma. Clin Radiol 67: 649-655

38. Hoffmann R, Rempp H, Schraml C et al (2015) Diffusion-weighted imaging during MR-guided radiofrequency ablation of hepatic malignancies: analysis of immediate pre- and post-ablative diffusion characteristics. Acta Radiol 56(8):908-916

39. Jiang T, Zhu AX, Sahani DV (2013) Established and novel imaging biomarkers for assessing response to therapy in hepatocellular carcinoma. J Hepatol 58:169-177

40. Sainani NI, Gervais DA, Mueller PR, Arellano RS (2013) Imaging after percutaneous radiofrequency ablation of hepatic tumors: part 1, normal findings. AJR Am J Roentgenol 200:184-193

41. Kim YS, Rhim H, Lim HK (2009) Imaging after radiofrequency ablation of hepatic tumors. Semin Ultrasound CT MR 30:49-66

42. Kim SK, Lim HK, Kim YH et al (2003) Hepatocellular carcinoma treated with radiofrequency ablation: spectrum of imaging findings. Radiographics 23:107-121

43. Kierans AS, Elazzazi M, Braga $L$ et al (2010) Thermoablative treatments for malignant liver lesions: 10-year experience of MRI appearances of treatment response. AJR Am J Roentgenol 194:523-529

44. Park MH, Rhim H, Kim YS, Choi D, Lim HK, Lee WJ (2008) Spectrum of CT findings after radiofrequency ablation of hepatic tumors. Radiographics 28 : 379-390

45. Park Y, Choi D, Lim HK et al (2008) Growth rate of new hepatocellular carcinoma after percutaneous radiofrequency ablation: evaluation with multiphase CT. AJR Am J Roentgenol 191:215-220

46. Agnello F, Salvaggio G, Cabibbo G et al (2013) Imaging in treated hepatocellular carcinoma. World J Hepatol 5(8):417-424

47. Di Stasi M, Ruscarini L, Livraghi T et al (1997) Percutaneous ethanol injection therapy in the treatment of hepatocellular carcinoma. A multicenter survey of evaluation practices and complication rate. Scand I Gastroenterol 32:1168-1173

48. Vossen JA, Buijs M, Kamel IR (2006) Assessment of tumor response on MR imaging after locoregional therapy. Tech Vasc Interv Radiol 9:125-132

49. Mannelli L, Kim S, Hajdu CH, Babb JS, Clark TW, Taouli B (2009) Assessment of tumor necrosis of hepatocellular carcinoma after chemoembolization: diffusion-weighted and contrast-enhanced MRI with histopathologic correlation of the explanted liver. AJR Am J Roentgenol 193:1044-1052

50. Hunt SJ, Yu W, Weintraub J, Prince MR, Kothary N (2009) Radiologic monitoring of hepatocellular carcinoma tumor viability after transhepatic arterial chemoembolization: estimating the accuracy of contrast-enhanced crosssectional imaging with histopathologic correlation. J Vasc Interv Radiol 20:30-38

51. Khankan AA, Murakami T, Onishi H et al (2008) Hepatocellular carcinoma treated with radio frequency ablation: an early evaluation with magnetic resonance imaging. J Magn Reson Imaging 27:546-551

52. Clark TW (2006) Complications of hepatic chemoembolization. Semin Intervent Radiol 23:119-125

53. Lee AJ, Gomes AS, Liu DM, Kee ST, Loh CT, McWilliams JP (2012) The road less traveled: importance of the lesser branches of the celiac axis in liver embolotherapy. Radiographics 32:1121-1132

54. Riaz A, Kulik L, Lewandowski RJ et al (2009) Radiologic-pathologic correlation of hepatocellular carcinoma treated with internal radiation using yttrium-90 microspheres. Hepatology 49:1185-1193

55. Ibrahim SM, Nikolaidis P, Miller FH et al (2009) Radiologic findings following Y90 radioembolization for primary liver malignancies. Abdom Imaging 34: 566-581

56. Keppke AL, Salem R, Reddy D et al (2007) Imaging of hepatocellular carcinoma after treatment with yttrium- 90 microspheres. AJR Am J Roentgenol 188:768-775

57. Alonzi R, Hoskin P (2006) Functional imaging in clinical oncology: magnetic resonance imaging- and computerised tomography-based techniques. Clin Oncol (R Coll Radiol) 18:555-570 
58. Taouli B, Koh DM (2010) Diffusion-weighted MR imaging of the liver. Radiology 254:47-66

59. Bammer R (2003) Basic principles of diffusion-weighted imaging. Eur J Radiol 45:169-184

60. Koh DM, Brown G, Riddell AM et al (2008) Detection of colorectal hepatic metastases using MnDPDP MR imaging and diffusion-weighted imaging (DWI) alone and in combination. Eur Radiol 18:903-910

61. van den Bos IC, Hussain SM, Krestin GP, Wielopolski PA (2008) Liver imaging at 3.0T: diffusion-induced black-blood echo-planar imaging with large anatomic volumetric coverage as an alternative for specific absorption rate-intensive echo-train spin-echo sequences: feasibility study. Radiology 248:264-271

62. Coenegrachts K, Delanote J, Ter Beek L et al (2007) Improved focal liver lesion detection: comparison of single shot diffusion-weighted echoplanar and single-shot T2 weighted turbo spin echo techniques. Br J Radiol 80:524-531

63. Low RN, Gurney J (2007) Diffusion-weighted MRI (DWI) in the oncology patient: value of breathhold DWI compared to unenhancedand gadoliniumenhanced MRI. J Magn Reson Imaging 25:848-858

64. Hardie AD, Naik M, Hecht EM et al (2010) Diagnosis of liver metastases: value of diffusion- weighted MRI compared with gadolinium-enhanced MRI. Eur Radiol 20:1431-1441

65. Elbarbary AA, Saleh Elahwal HM, Elashwah ME (2015) Role of diffusionweighted magnetic resonance imaging in evaluation of hepatic focal lesions. Egypt J Radiol Nucl Med 46:325-334

66. Piana G, Trinquart L, Meskine N, Barrau V, Beers BV, Vilgrain V (2011) New MR imaging criteria with a diffusion-weighted sequence for the diagnosis of hepatocellular carcinoma in chronic liver diseases. J Hepatol 55:126-132

67. Vandecaveye V, De Keyzer F, Verslype C et al (2009) Diffusion-weighted MRI provides additional value to conventional dynamic contrast-enhanced MRI for detection of hepatocellular carcinoma. Eur Radiol 19:2456-2466

68. Catalano OA, Choy G, Zhu A et al (2010) Differentiation of malignant thrombus from bland thrombus of the portal vein in patients with hepatocellular carcinoma: application of diffusion-weighted MR imaging. Radiology 254:154-162

69. Wagner M, Doblas S, Daire JL et al (2012) Diffusion-weighted MR imaging for the regional characterization of liver tumors. Radiology 264: 464-472

70. Gluskin JS, Chegai F, Monti S, Squillaci E, Mannelli L (2016) Hepatocellular carcinoma and diffusion-weighted MRI: detection and evaluation of treatment response. J Cancer 7(11):1565-1570

71. Kamel IR, Liapi E, Reyes DK, Zahurak M, Bluemke DA, Geschwind JF (2009) Unresectable hepatocellular carcinoma: serial early vascular and cellular changes after transarterial chemoembolization as detected with MR imaging. Radiology 250:466-473

72. Kamel IR, Bluemke DA, Ramsey D et al (2003) Role of diffusionweighted imaging in estimating tumor necrosis after chemoembolization of hepatocellular carcinoma. AJR Am J Roentgenol 181:708-710

73. Chapiro J, Wood LD, Lin M et al (2014) Radiologic-pathologic analysis of contrast-enhanced and diffusion-weighted MR imaging in patients with HCC after TACE: diagnostic accuracy of 3D quantitative image analysis. Radiology 273:746-758

74. Bonekamp S, Jolepalem P, Lazo M, Gulsun MA, Kiraly AP, Kamel IR (2011) Hepatocellular carcinoma: response to TACE assessed with semiautomated volumetric and functional analysis of diffusion-weighted and contrast-enhanced MR imaging data. Radiology 260:752-761

75. Sahin H, Harman M, Cinar C, Bozkaya H, Parildar M, Elmas N (2012) Evaluation of treatment response of chemoembolization in hepatocellular carcinoma with diffusion-weighted imaging on 3.0-T MR imaging. J Vasc Interv Radiol 23:241-247

76. Yuan Z, Li WT, Ye XD, Peng WJ, Xiao XS (2014) Utility of diffusion-weighted imaging to assess hepatocellular carcinoma viability following transarterial chemoembolization. Oncol Lett 8:831-836

77. Kokabi N, Camacho JC, Xing M et al (2014) Apparent diffusion coefficient quantification as an early imaging biomarker of response and predictor of survival following Yttrium-90 radioembolization for unresectable infiltrative hepatocellular carcinoma with portal vein thrombosis. Abdom Imaging 39:969-978

78. Rhee TK, Naik NK, Deng J et al (2008) Tumor response after Yttrium-90 radioembolization for hepatocellular carcinoma: comparison of diffusionweighted functional MR imaging with anatomic MR imaging. J Vasc Interv Radiol 19:1180-1186
79. Park HJ, Kim SH, Jang KM, Lee SJ, Park MJ, Choi D (2013) Differentiating hepatic abscess from malignant mimickers: value of diffusion-weighted imaging with an emphasis on the periphery of the lesion. J Magn Reson Imaging 38:1333-1341

80. Yu Jl, Park HC, Lim DH et al (2014) The role of diffusion-weighted magnetic resonance imaging in the treatment response evaluation of hepatocellular carcinoma patients treated with radiation therapy. Int J Radiat Oncol Biol Phys 89:814-821

81. Schraml C, Schwenzer NF, Martirosian P et al (2009) Diffusion-weighted MRI of advanced hepatocellular carcinoma during sorafenib treatment: initial results. AJR Am J Roentgenol 193:W301-W307

82. Kele PG, van der Jagt EJ (2010) Diffusion weighted imaging in the liver. World J Gastroenterol 16:1567-1576

83. Schraml C, Schwenzer NF, Clasen S et al (2009) Navigator respiratory-triggered diffusion-weighted imaging in the follow-up after hepatic radiofrequency ablation-initial results. J Magn Reson Imaging 29:1308-1316

84. Yuan Z, Ye XD, Dong S et al (2010) Role of magnetic resonance diffusionweighted imaging in evaluating response after chemoembolization of hepatocellular carcinoma. Eur J Radiol 75:e9-e14

85. Shao H, Ni Y, Zhang J, et al (2013) Dynamic contrast-enhanced and diffusion-weighted magnetic resonance imaging noninvasive evaluation of vascular disrupting treatment on rabbit liver tumors. PLoS One 8:e82649

86. Kim SY, Lee SS, Byun JH et al (2010) Malignant hepatic tumors: short-term reproducibility of apparent diffusion coefficients with breath-hold and respiratory-triggered diffusion-weighted MR imaging. Radiology 255:815-823

87. Kim SY, Lee SS, Park B et al (2012) Reproducibility of measurement of apparent diffusion coefficients of malignant hepatic tumors: effect of DWI techniques and calculation methods. J Magn Reson Imaging 36:1131-1138

88. Padhani AR, Liu G, Koh DM et al (2009) Diffusion-weighted magnetic resonance imaging as a cancer biomarker: consensus and recommendations. Neoplasia 11:102-125

89. Kokabi N, Camacho JC, Xing M, Edalat F, Mittal PK, Kim HS (2015) Immediate post-doxorubicin drug-eluting beads chemoembolization MR apparent diffusion coefficient quantification predicts response in unresectable hepatocellular carcinoma: a pilot study. J Magn Reson Imaging 42(4):981-989

90. Kokabi N, Ludwig JM, Camacho JC, Xing M, Mittal PK, Kim HS (2015) Baseline and early MR apparent diffusion coefficient quantification as a predictor of response of unresectable hepatocellular carcinoma to doxorubicin drug-eluting bead chemoembolization. J Vasc Interv Radiol 26(12):1777-1786

91. Dong S, Ye XD, Yuan Z, Xu LC, Xiao XS (2012) Relationship of apparent diffusion coefficient to survival for patients with unresectable primary hepatocellular carcinoma after chemoembolization. Eur J Radiol 81:472-477

92. Goshima S, Kanematsu M, Kondo H et al (2008) Evaluating local hepatocellular carcinoma recurrence post-transcatheter arterial chemoembolization: is diffusion-weighted MRI reliable as an indicator? J Magn Reson Imaging 27:834-839

93. Hagiwara M, Rusinek H, Lee VS et al (2008) Advanced liver fibrosis: diagnosis with 3D whole-liver perfusion MR imaging-initial experience. Radiology 246:926-934

94. Abdullah SS, Pialat JB, Wiart M et al (2008) Characterization of hepatocellular carcinoma and colorectal liver metastasis by means of perfusion MRI. J Magn Reson Imaging 28:390-395

95. Patel J, Sigmund EE, Rusinek H, Oei M, Babb JS, Taouli B (2010) Diagnosis of cirrhosis with intravoxel incoherent motion diffusion MRI and dynamic contrast-enhanced MRI alone and in combination: preliminary experience. J Magn Reson Imaging 31:589-600

96. Jarnagin WR, Schwartz LH, Gultekin DH et al (2009) Regional chemotherapy for unresectable primary liver cancer: results of a phase II clinical trial and assessment of DCE-MRI as a biomarker of survival. Ann Oncol 20:1589-1595

97. Yopp AC, Schwartz LH, Kemeny N et al (2011) Antiangiogenic therapy for primary liver cancer: correlation of changes in dynamic contrast-enhanced magnetic resonance imaging with tissue hypoxia markers and clinical response. Ann Surg Oncol 18:2192-2199

98. Wang D, Gaba RC, Jin B et al (2011) Intraprocedural transcatheter intraarterial perfusion MRI as a predictor of tumor response to chemoembolization for hepatocellular carcinoma. Acad Radiol 18:828-836

99. Taouli B, Johnson RS, Hajdu C et al (2013) Hepatocellular carcinoma: perfusion quantification with 3D perfusion-weighted MR imaging. AJR Am J Roentgenol 201(4):795-800 
100. Thng CH, Koh TS, Collins DJ, Koh DM (2010) Perfusion magnetic resonance imaging of the liver. World J Gastroenterol 16:1598-1609

101. Padhani AR (1999) Dynamic contrast-enhanced MRI studies in human tumours. Br J Radiol 72:427-431

102. Padhani AR (2002) Dynamic contrast-enhanced MRI in clinical oncology: current status and future directions. J Magn Reson Imaging 16:407-422

103. Wang J, Chen LT, Tsang YM, Liu TW, Shih TT (2004) Dynamic contrastenhanced MRI analysis of perfusion changes in advanced hepatocellular carcinoma treated with an antiangiogenic agent: a preliminary study. AJR Am J Roentgenol 183:713-719

104. Miyazaki K, Collins DJ, Walker-Samuel S et al (2008) Quantitative mapping of hepatic perfusion index using MR imaging: a potential reproducible tool for assessing tumour response to treatment with the antiangiogenic compound BIBF 1120, a potent triple angiokinase inhibitor. Eur Radiol 18: 1414-1421

105. Sahani DV, Holalkere NS, Mueller PR, Zhu AX (2007) Advanced hepatocellular carcinoma: CT perfusion of liver and tumor tissue-initial experience. Radiology 243:736-743

106. Woo S, Lee JM, Yoon JH, Joo I, Han JK, Choi BI (2014) Diffusion-weighted imaging of hepatocellular carcinoma. Radiology 270:758-767

107. Woo S, Lee JM, Yoon JH, Joo I, Han JK, Choi BI (2014) Intravoxel incoherent motion diffusion-weighted MR imaging of hepatocellular carcinoma: correlation with enhancement degree and histologic grade. Radiology 270:758-767

108. Mürtz P, Penner A, Pfeiffer A et al (2016) Intravoxel incoherent motion model-based analysis of diffusion-weighted magnetic resonance imaging with $3 \mathrm{~b}$-values for response assessment in locoregional therapy of hepatocellular carcinoma. Onco Targets Ther 9:6425-6433

109. Granata V, Fusco R, Catalano O et al (2016) Intravoxel incoherent motion (IVIM) in diffusion-weighted imaging (DWI) for hepatocellular carcinoma: correlation with histologic grade. Oncotarget 48:79357-79364

\section{Submit your manuscript to a SpringerOpen ${ }^{\circ}$ journal and benefit from:}

- Convenient online submission

- Rigorous peer review

- Open access: articles freely available online

- High visibility within the field

- Retaining the copyright to your article

Submit your next manuscript at $\boldsymbol{\nabla}$ springeropen.com 